Int. J. Electrochem. Sci., 13 (2018) $4808-4816$

\title{
Synthesis of a Flavone-Titanium (IV) Complex and Its Electrocatalytic Activity
}

\author{
Hongfang Lai and Ruisong Wei \\ College of Chemistry and Bio-engineering Hechi University, Hechi, Guangxi, 546300, P.R. China \\ *E-mail: ruisongwei_eric@foxmail.com
}

doi: $10.20964 / 2018.05 .18$

Received: 21 November 2017 / Accepted: 22 January 2018 / Published: 10 April 2018

This work reported the synthesis and measurements of a novel complex of primuletin (a flavone of natural origin) and titanium. Through changes in the electron density, the $3 \mathrm{HF}$ ligand was found to have the ability to bind to the metal salt through electrochemical experiments. The Ti(IV)-primuletinmulti-walled carbon nanotube (MWCNT)-PE showed an enhanced current response and high reversibility. Additionally, it exhibited desirable electrocatalytic activity in hydroxylamine oxidation. A linear relationship was found between the catalytic current response (measured through amperometry) and the hydroxylamine concentration over a range of $2.5 \mu \mathrm{M}$ to $0.4 \mathrm{mM}$.

Keywords: Primuletin; Flavone-titanium (IV) complex; Flavone; Electrochemical oxidation

\section{$\underline{\text { FULL TEXT }}$}

(C) 2018 The Authors. Published by ESG (www.electrochemsci.org). This article is an open access article distributed under the terms and conditions of the Creative Commons Attribution license (http://creativecommons.org/licenses/by/4.0/). 